\title{
An Exploratory Study of Determinants and Corrective Measures for Software Piracy and Counterfeiting in the Digital Age
}

Yin-Leng Theng (Corresponding author)

Wee Kim Wee School of Communication and Information

31 Nanyang Link, Singapore 637718

Tel: 65-6790-5834Ｅ-mail: tyltheng@ntu.edu.sg

Wee Teck Tan

Microsoft Corporation., 159th PL NE, Redmond, WA 98052, USA

Tel: 1-425-590-7878Ｅ-mail: WeeTeck.Tan@microsoft.com

May O. Lwin

Wee Kim Wee School of Communication and Information

31 Nanyang Link, Singapore 637718

Tel: (65) 6790-6669Ｅ-mail: tmaylwin@ntu.edu.sg

Schubert Foo Shou-Boon

Wee Kim Wee School of Communication and Information

31 Nanyang Link, Singapore 637718

Tel: 65-6513-8122 E-mail: assfoo@ntu.edu.sg

\begin{abstract}
Software piracy and counterfeiting is a global problem that has resulted in huge economic losses worldwide. This paper proposes a theory-based approach to study the key factors contributing to piracy and counterfeiting issues. We first developed a theoretical model linking the antecedents into the key factors using information acquired from an extended literature review. We then undertook a survey of thirty business professionals representing different industries, functional roles and different levels of work exposure to software usages in Singapore to investigate the issues. Specifically, the objectives of the survey were to: (1) investigate the key issues associated to software piracy and counterfeiting; (2) identify the factors that have contributed to the software piracy and counterfeiting; and (3) draw up a refined list of appropriate measures to counter software piracy and counterfeiting. Through the structural use of Non-Parametric Correlation Test, Chi-Square Test for Independence, Fisher Exact Probability Test and Phi value, our findings showed that the lack of awareness to software usage laws and regulations, the perceived lack of enforcement measures and penalties, and the lack of educational programs catering to the proper usage of software were the key factors contributing to the software piracy and counterfeiting issues. The findings are useful to managers of software companies and policy-makers in reviewing existing software protection policies, laws and regulations, such that any flaws or loopholes can be identified.
\end{abstract}

Keywords: Software piracy, Counterfeiting, Measures, Singapore

\section{Global Problem of Software Piracy and Counterfeiting}

Software piracy, defined as the unauthorized utilization, replication, and distribution of commercially available or copyrighted software (Yang, Sonmez, Bosworth, \& Fryxell, 2008), has been increasing over the years. A report by the Business Software Alliance (BSA, 2009) noted that for the past five years worldwide, software piracy has hovered between $35 \%$ to $38 \%$, and losses amounted to billions of dollars. The prevalence and significant growth of software piracy in the past four decades since the advent of computer technology has warranted attention from researchers, software developers, educators, intellectual property advocators and the like. Despite the use of deterrent (hinder the use of pirated software by means of legal sanctions) and preventive (impede the act of software piracy by depleting and expending the pirates' resources) measures to combat software piracy (Gopal \& Sanders, 1997), this problem seems unabated. 
In order that the methods and findings of our study provide a background to the determinants and corrective measures for software piracy and counterfeiting made in this paper, we will provide a brief discussion of related concepts in the ownership, sharing and use of resources. Ownership or right to use of resources produced may be legally protected by a copyright, patent, trademark, etc. In fact, the WIPO (World Intellectual Property Organization) defines intellectual property of resources as creations of the mind which includes inventions, literary and artistic works, symbols, names, images and designs used in commerce. The word "property" implies that it carries a value to a certain extent and there is an owner associated to it. On the other hand, "intellectual" implies that it is something that cannot be grabbed hold of physically and protected easily. Intellectual property is a product that is intangible, originated from human intellect and can be expressed, distributed or passed on by any available means of tangible mediums. For example, intellectual property includes industrial, literary, and artistic works (Hawamdeh and Hart, 2002). Like physical property, the value of intellectual property comes from the fact that it can be appreciated, shared, transmitted and distributed. However, intellectual property of resources can be stolen without depriving the owner of it, a commodity which can be extremely valuable, and yet falls outside the normal political and social definitions (Chesterman and Lipman, 1988).

Piracy, on the other hand, is a copy or duplication of intellectual property without seeking the consent of the owner or author. In contrast, at a more complex level of counterfeiting, the pirated product is being intentionally built to look genuine. Counterfeiters are mostly motivated by greed because they are out to make easy money from someone else's work at the expense of the author.

Historically, authors of intellectual works had perceived the inventor of photocopying machine as a "sinner" because this tool allowed original printed works to be copied by anyone and very often at a low cost. Most of the blame on printed works piracy were attributed to the invention of photocopiers. Subsequently, creators of audio and video had the same concern when electronic manufacturers announced the invention of a series of devices starting from tape recorder then to video tape recorder. As documented by Chesterman and Lipman (1988) in the Betamax, Toshiba and Amstrad cases, there were then attempts by the music companies and movie makers to halt the proceeds of these technological advancements because essentially with these newdevices, duplicating music or movies was made simple.

Technology has, therefore, made copying of intellectual property easier, faster and cheaper. In the past, the thought of copying an entire book by hand was enough to stop anyone from proceeding (Hawamdeh and Hart, 2002). Indeed, the worst nightmare for the owner of digital intellectual property has arrived as the world embraces one of the greatest inventions of mankind in micro-computer technology software.

In a study of 309 students by Cohen (1989), he found that attitude of the students is relevant to software piracy behaviour with $69 \%$ who thought that software piracy was acceptable. In previous related studies, Peace (1997), Gopal \& Sanders (1997) found that software piracy was influenced by the age and gender of the respondents with younger male respondents engaged more in software piracy. Sims, Cheng \& Teegen (1996) also showed that the demographics of the individual such as gender, age and educational background influences their attitude towards software piracy.

Copyright is a legal term used to describe rights given to creators for their literary and artistic works. This gives the original creators of works the exclusive rights to use or authorize others to use the work as agreed, and one of such rights is the reproduction rights. Computer program is a form of literacy works and has been included under the umbrella of works covered by copyrights as defined by WIPO. Software piracy is the attempt to make illegal copies from an original piece of software program and sell those illegal copies to consumers. Software counterfeiting is to package the pirated contents such that the result of the illegal software product "look and feel" as genuine as the original one. However, whether it is piracy or counterfeiting, the primary intent is similar and that is to copy someone else's work without formally seeking permission from the author.

\section{Research Questions and Review of Key Factors}

\subsection{Research Questions}

Addressing issues related to software piracy or counterfeiting is an on-going challenge. While software companies and lawmakers have developed and attempted corrective measures to fight the trend of piracy through copy-protected software, product identification key, hardware dongle, anti-piracy campaigns, schemes that offer monetary rewards for any reports of software, the problem of privacy remains prevalent and significant. As such, in this study, we ask three pertinent research questions (RQs) on software misuse (that is, software piracy and counterfeiting), and measures taken to deal with software misuse:

- RQ1. Is there currently any general trend of software misuse? 
- RQ2. If there is a trend of software misuse, what factors contribute to this trend?

- RQ3. Whether measures aimed to fight piracy and counterfeiting are appropriate and correct? What then are appropriate and correct measures?

We explore these questions through a pilot study on software misuse and measures in Singapore. In Singapore alone, the BSA study found that Singapore had a piracy rate of $43 \%$, with piracy losses amounting to US\$96 million (BSA, 2004). Although, in the 2008 study, the piracy rate has gradually reduced to $36 \%$ but with increased reported losses of US\$163 million (BSA, 2009), software misuse in Singapore is still prevalent.

\subsection{Review of Key Factors}

The 2009 report analysed that forces that reduced piracy in many countries included vendor-driven legalization programs, education and enforcement actions by governments and BSA, and technology shifts, such as the increased deployment of digital rights management (BSA, 2009). On the contrary, the report explains that the forces that increased piracy, or prevented significant declines in piracy rates, included the rapid growth of the consumer PC market, activity in the base of older computers where unauthorized software may replace previously pirated software, expanding access to the Internet, and the increasing sophistication of software pirates (BSA, 2009).

To address the abovementioned RQs, first, we reviewed challenging issues as highlighted in BSA reports (BSA, 2004; 2005; 2006; 2008; 2009) and summarized in four key factors in: (i) technology; (ii) government and politics; (iii) business practice; and (iv) consumer mindset, and supporting variables associated to the software piracy and counterfeiting issues. Second, we developed a theoretical model linking the antecedents into the key factors using information acquired from extended literature review. Third, the research model then underlies the construction of the survey instrument.

\subsubsection{Technology}

Information, previously available only in analogue form, is now readily available in digital form. With the introduction of CD (Compact Disc), VCD (Video Compact Disc), DVD (Digital Video Disc), MD (Mini Disc) and many other commonly available cost-effective storage solutions, the transition from analogue to digital means that huge chunks of data could be easily packed into one single medium. Digitization has brought more uncertainties on how intellectual property should be protected. Computer users recognize the ease with which software could be copied and exchanged (Gunney, 1990). In fact, the digital technology has essentially eliminated the conventional barriers to mass copying and broad distribution. This presents obvious opportunity for copying an author's software work without consent. Presently, there is no clear definition on what truly constituted a violation of copyright or improper use of software intellectual property.

Now, as information enters cyberspace, the native home of mind, these bottles are vanishing. Opportunists do not need reminder on the ease of access to digital information, software or Barlow's free flow of "Wine". They have recognized the immediate potential for hugely effortless rewards. With the rapid growth of broadband connections to the Internet, the rise in peer-to-peer networks and information sharing technology such as BitTorrent, the problem of software piracy seems set to exacerbate in the coming years (Hill, 2007). Hence, supporting variables identified as related to the Technology factor were:

- Computer technologies that facilitated easy access to software.

- Copy-enabled technologies that allowed software programs to be copied easily.

- Copy protection technologies that were developed specifically to prevent copying of software programs.

\subsubsection{Government and Politics}

Piracy is one of the symptoms of a business revolution, part of the massive change now taking place in market forces and world economies. However, these issues are complicated as they involve political implications due to growing role of national governments, being dragged in as negotiators, as enforcers, or even, in the Third World, as protectors of piracy (Chesterman and Lipman, 1988). These responsibilities are new to political theory and provoke different and often contradictory responses. Software intellectual properties had generally originated from well-developed countries. These countries have, by default of their abilities to innovate ahead of weaker or under-developed countries, led the world in the digitization of intellectual property. This imbalance has created a technological gap between developed and developing countries. Chesterman and Lipman (1988) described the different notions held by governments on the issue of piracy:

a. Enforcing Software Copyright. Some developing countries took the stance of supporting the notion of having ownership associated to software property or, software copyright. By acknowledging software 
copyright, the governments of developing countries were therefore supporting the fact that software owners were entitled to be paid for their creations. There exists perception that the acknowledgement of intellectual property rights equates the protection for monopoly imports (UNCTAD, 1975). In discussing the myths of weak protection, Sherwood (1990) summarized the various propositions cited to support national policies of weak protection for intellectual property into four basic propositions: (i) saving the country money; (ii) promoting local industry; (iii) helping to acquire technology and; (iv) lessening dependency. Therefore, without compelling justifications, governments of developing countries are often forced into less than moderate approach to software copyrights. Lesser (2001) argued that too strong protection in countries with limited research and development capacity, protection which reduces local production of "pirate" products, would reduce welfare due to higher process and job loss. On the other hand, supporting copyright was certainly useful in the international dealings between developing and developed countries. One key advantage was the credibility of the government and the status of trust acknowledged at an international level because these goodwill were really helpful in the negotiations for international funding, economic aids, foreign investments, trade concessions and so on. To keep these deals going and unchallenged, governments of developing countries would be compelled to enforce the copyright laws domestically.

b. Supporting Software Copyright. The stance to support enforcement posed a domestic challenge to the governments of developing countries because of the massive impact on the consumer if the government chose to support the notion of copyright. It was apparent that consumers in developing countries spend on daily necessities rather than on technology-enhanced goods such as software programs. The same situation applied to businesses from these developing countries whereby business operations were less technologically supported. Chesterman and Lipman (1988) argued that local businesses often acquire pirated or counterfeited technologically-enhanced goods such as software programs to help to propel businesses forward. Even when copyright laws were acknowledged by governments of developing countries, the question remains as to whether the applicable laws were being enforced domestically. In most situations, governments appear to be reluctant or slow to tackle the domestic software piracy and counterfeiting issues. The rationale for this was political interest and as Gurnsey (1995) puts it, indeed there is a depressing inevitability in several countries over the unwillingness of politicians to put their self interests ahead of national responsibilities in the copyrights matter. Given the presumably poorer state of economic conditions in these developing countries, the people and businesses would be deprived of the opportunity to enjoy lower cost and often free software products.

Therefore, supporting variables related to the Government and Politics factor were identified as:

- The legal framework that defined how software programs should be protected.

- Regulations and enforcement that addressed the issue of violation and enforcement.

- Technology gap that determined how much balance is needed between software protection and software fair use.

\subsubsection{Business Practice}

Much of the software piracy and counterfeiting problems seem to stem from business policies on software property. The internal control of information, the information security policies and software usage policies played a big part in the software piracy and counterfeiting issues. Very often, the lack of good internal control had opened up the floodgate for employees to access exclusive information freely and without restrictions. This may have caused protected information to stray and subsequently being made available to the software pirates or counterfeiters. Most companies provide employees with networking, internet and email accesses, technologies which are in place to provide employees timely access to mission-critical information and as well as sharing of software programs. These technologies have also subjected the companies to the extended risk of software property being abused by the employees. The ability to transact and react quickly to external business climate is critical to the success of the new world business models. This ability was driven by the rapid deployment of software applications and tools. From the perspective of businesses that relied heavily on the use of software, several issues have arisen:

a. The pace of implementing these software applications and tools has been too quick that over time, companies tend to build up significant inventories of software programs. Thus, strong internal software usage policies are needed to ensure that appropriate control measures are taken to keep stock of the software inventories and, to avoid possible misuses.

b. As businesses needs continue to grow, more advanced and powerful applications would be needed to 
support growing business needs. Continuous upgrade and expansion of software inventories would have taken significant toll on business budgets. Therefore, as businesses relied more and more on the acquisition of new software programs, the costs of fulfilling these increasing business needs would be growing due to more budgets being required for acquisition of more sophisticated software.

c. With more adoption of software applications and tools, employees would be spending significant amounts of time using software programs. There would be a need to address employees' responsibilities and rights associated to the proper usage of software programs.

Consequently, certain software companies subcontracted or outsourced their supply chain, marketing and selling aspect of their businesses, with the aim of reducing the resources needed to engage in such activities in order that the focus on most of these resources can be on the core business activities. This practice was adopted because software owner could focus wholly on refining products and offering consumers the best of product quality. The downside was that valuable information would be in the hands of external parties. Unless the owners have adopted strict criteria for selecting responsible agents, the risk of digital intellectual property's exposure to piracy and counterfeiting could be very high. Even if these owners exercised close scrutiny on what appointed agents were doing, the actions of the agents' employees were most often difficult to control or monitor.

Paying for software products may be reasonable for consumers in developed countries but not for those living in developing countries. If the price remained the same in the developing countries, it could be too expensive for ordinary consumers. For instance, the rights owners may be reluctant to be accommodative in terms of pricing their products to fall within the spending power of consumers in the developing countries. Lowering the price of software might be interpreted as lowering quality from the perspective of consumers who can actually afford to pay for the software products. We identified the following supporting variables relating to the Business Practice factor:

- The legal framework that defined how software programs should be protected.

- Regulations and enforcement that addressed the issue of violation and enforcement.

- Technology gap that determined how much balance is needed between software protection and software fair use.

\subsubsection{Consumer Mindset}

One reason why software owners did not see the urgent need to reduce software prices could be because consumers in developing countries could not afford basic high-tech devices such as computers. The revenue loss as such would be small given the poorer economic state of these countries. In addition, there were little chances of prosecuting the consumers or, the software pirates and counterfeiters, given that there were gaps in the laws and enforcement policies in these regions. It was also probably not worth the effort since the population who could actually own computers from these developing countries was small.

On the other hand, if the software owners agreed to lower the software prices in the developing countries, it is also possible that these lower-priced software products would be re-imported into the developed countries. Therefore, software producers price their product according consumers' buying power rather than pegging prices to cheaper, pirated or counterfeited software products Could any software products sustained competition against their cheaper and illegitimate versions in these developing countries without the appropriate "interactions" or reaction to the demand generated by price mechanism? Cosovanu (2006) proposed that "open source software is likely to be a central part of the answer, but may face an uphill battle in a context where the dominant proprietary software packages already have a lock-in on most of the emerging markets, the network effect in their favor working, ironically, through piracy".

Hence, what is challenging is not whether business practices were right, but to understand the influence these business practices had on consumers. The message sent by software owners to consumers from the very onset was confusing. As a result, whenever consumers showed a preference for pirated and counterfeited software over the genuine ones, there would be software pirates and counterfeiters who were always prepared to supply them.

From the scenario we discussed, it was realistic to assume that the severity of the issue around software piracy and counterfeiting boiled down to consumers' demand for these non-genuine software products and how consumers perceived software as intellectual property. We could also assume that without any significant interest from consumers, pirated or counterfeited software products would have also lost their relevance. On the other hand, was it the low awareness level to the implications of software copyrights, and the laws and regulations that shaped the mindset? Hence, supporting variables identified relating to the Consumer Mindset factor were: 
- Easy access to technology influences the mindset of software consumers on correct software usage.

- Training and education programs improve software users' understanding on the implication of software laws and regulations.

- High cost of software ownership shape software consumers' mindset on the issue of copyrights.

\subsection{Formulation of Theoretical Framework}

In the previous section, we identified four main factors in the areas of Technology, Government and Politics, Business Practices and Consumer Mindset that might directly or indirectly influence software piracy and counterfeiting. It can be further observed that these four factors were inter-related through the presence of several key supporting variables. For example in discussing the Technology factor, the key contributing variables to the Technology factor were "copy-enabled technologies", "copy protection technologies" and "computer technologies". In addition, the "copy protection technologies" variable was related to the "security and measures" variable and which in turn, supported the Business Practices factor. Furthermore, the "copy protection technologies" variable was also related to the "access to technology" variable which in turn has an influence on the Consumer Mindset factor. In summary, twelve supporting variables (SVs) were identified as related to each of the four main factors (see Table 1).

The term "software piracy and counterfeiting issue" will be used interchangeably with another common term known as "software misuse trend" throughout this paper. Piracy in the traditional sense of duplicating physical video tapes, audio tapes, books printing, photocopying and etc, are included as part of this study. The survey gathered data on consumer and business software demands from the targeted software user population based in Singapore. However, company specific materials or internal company information resources were not collected in this survey.

Table 1 shows a summary of the key variables supporting each of the main factors leading to software piracy and counterfeiting. Figure 1 illustrates a high-level overview on the association of the four main factors through linking the supporting variables is depicted by the relationship diagram.

[Insert Table 1]

[Insert Figure 1]

\section{The Study}

\subsection{Motivation and Objectives}

The objectives of the survey study were to: (i) determine if there is a general trend of software misuse;; (ii) identify the key issues and factors that have contributed to the software piracy and counterfeiting issue; and (iii) draw up a refined list of appropriate measures to counter software piracy and counterfeiting.

In identifying objectives of the study to investigate the four factors and the supporting variables, reviews carried out included published works related to software piracy and counterfeiting; internet contents published by authentic sources such as WIPO (World Intellectual Property Organization) and BSA (Business Software Alliance); and the regular work interactions with key parties involved in the anti-piracy research and field investigation works.

\subsection{Study Design and Protocol}

Surveys are used to address users' subjective opinions through interviews or questionnaires (Preece et al., 1993). A questionnaire was evaluated to be an appropriate instrument in this survey study to gather the required data. The decision to adopt the questionnaire was based on the following reasons: (i) the need to collect data showing the most current state of software usage pattern; (ii) the need for an efficient means of distributing and collecting feedback from audiences across different demographics; and (iii) the need to gather restricted information related to the respondents' companies and therefore questionnaire rather than personal meeting would have placed the respondents at ease in answering these questions.

\subsubsection{Data Collection and Data Types}

The survey was conducted from March to June 2005, seeking responses from current full-time employees working within Singapore with exposure to the use of computer technology. To ensure optimal diversity, the questionnaire was administrated in batches with each batch covering respondents from different industries such as financial, manufacturing, technology, education, etc. with functional roles such as senior management, middle management, individual contributor, etc. Email was used as a tool to send out the questionnaire and respondents were given the option of replying either via email or hard copies print out. 
To ensure that the data collected would be relevant to the supporting variables listed in Figure 1, the key focuses of the data collection effort include: (i) data on the current software deployment and software management practices adopted by companies operating in Singapore; (ii) data on the current state of user awareness level with regard to software usage rights and the accompanying laws and regulations governing software usages and, as well as technologies affecting software usages; and (iii) data on the users' views on software usage driven by factors such as technologies, laws and regulations, business needs and budget.

\subsubsection{Questionnaire Design}

The questionnaire was designed to address the research objectives to investigate the key issues associated to software piracy and counterfeiting; to identify the key factors that have contributed to the software piracy and counterfeiting issue; and to draw up a refined list of appropriate measures to counter software piracy and counterfeiting. Drawing upon the conceptual model (Figure 1) focusing on the four key factors and the research objectives, the questionnaire specifically addresses the following questions:

a. Is there currently any general trend of software misuse that can be reported from the data gathered through the questionnaire?

b. If there is a trend of software misuse, can the data gathered from the questionnaire then agree that this trend is contributed by one or more of these four factors listed?

- Technology

- Government and Politics

- Business Practice

- Consumer Mindset

c. In addition to the four factors, can the data gathered from the questionnaire suggest any additional factors that are contributing to the software misuse trend?

d. Are there any new themes or issues associated to the software misuse trend that can be identified from the questionnaire data?

The questionnaire consisted of five sections. With the exception of Section A, the questions from Sections B to $\mathrm{E}$ were set out thematically in accordance to the four key factors discussed in Figure 1:

- Section A is concerned with gathering general employment information from each respondent.

- Section B addresses the Technology Factor, and was concerned with gathering data that were associated to the respondents' exposure level to current computing technologies.

- Section $\mathrm{C}$ is concerned with the Government and Politics Factor, gathering data related to the respondents' views and awareness level on laws and regulations pertaining to software usage.

- Section D deals with the Business Factor, and was concerned with gathering data related to the organizations that the respondents work in.

- Section E concentrates on the Consumer Mindset Factor, and was concerned with gathering data related to the respondents' views on a set of scenarios that described the relation of software usage with other factors such as affordability and accountability.

\subsubsection{Challenges Faced in Questionnaire Formulation}

In designing the questionnaire, two key challenges were met. Firstly, the scope of the data context was wide ranging and would likely lead to the inclusion of questions which did not fit into the research boundary. To work around it, a criterion was set to ensure that any question to be considered for inclusion must fall within the context of Figure 1. Secondly, the questionnaire was intended to seek sensitive feedback related to software piracy and counterfeiting. Respondents were thus required to provide their views on the software usage trend based upon what they knew about the organizations they currently work for. While direct questions would have drawn answers that reflected the true picture, it was highly unlikely that candid responses could be expected, given the sensitivity of the issue on hand. Therefore, the questions were phrased mostly indirectly, and at the same time, carefully chosen words were used so as to draw answers that would truly reflect the current state of affair.

However, one other setback using questionnaire as the data collection instrument was apparent. As most questionnaire information gathered from respondents may not be as thorough as desired and as such there is no further avenue to drill further into details should the need arises. Moreover, considerations must also be made to 
possible answer omission by some respondents.

\section{Data Coding and Preparation}

\subsection{Data Coding}

For all the questions in the questionnaire, there were at least four categories of probable answers provided. For each question, the respondents were asked to indicate their opinion on a five-point Likert scale, choosing one that best fitted their opinion. An example of the scale might be [Strongly Agree, Agree, Disagree, Strongly Disagree, Not Applicable].

The questionnaire was created using online word processing software and the respondents were asked to fill the answers directly into the online questionnaire document. This way, a standardized response format from each respondent was expected. The approach to adopt a standardized response was to ensure that the data gathered were well-structured and fell within the context of the issues under investigation. In addition, this offered the advantages of having the data being categorized and compiled very quickly for analysis. On the other hand, one drawback to this approach was that since the issue of software piracy and counterfeiting was wide scope in nature, there could also be some critical information omitted as a result of using a restrictive response format. To minimize the chances of missing out on any important responses that could be critical to the study, an additional answer option was included whenever applicable to allow respondents to provide further views to each question grouping.

Each answer category to a question ranging from "very effective" to "no/invalid answer" was coded with numeric values of " 0 " to " 4 " respectively. As mentioned earlier, in addition to the probable answer categories that were provided for each question, whenever applicable, respondents were also provided with an arbitrary option of providing further views to each question or question grouping. However, these additional views if any were not coded but were used instead as additional information for consideration during data analysis. Through pilot study, initial feedback was gathered from a small group of respondents. The feedback was implemented through several iterations of revision. Table 2 shows the constructs, supporting variables and measure scales used.

\section{[Insert Table 2]}

\subsection{Data Analysis}

The following outlined the steps undertaken in analyzing the data collected from the questionnaire:

a. Data gathered from the questionnaire were transformed into bar charts to facilitate observation.

b. The test on the data was conducted on the measurement model to determine the convergent and discriminant validity tests of the instrument items.

c. Observation was made on Questions D13 to D18 with the objective of finding answer to RQ1. Questions D13 to D18 were deliberately crafted so that the answers that were drawn from these questions could be used as predictor of software misuse trend:

- D13 - Software inventory audit

- D14 - Education or training on correct software use

- D15 - Housekeeping to ensure software usage compliance

- D16 - Company wide software usage compliance alerts or reminders

- D17 - Review/Update existing software usage processes and policies

- D18 - Taking disciplinary action against software misuse

d. Having confirmed the software misuse trend, Questions D13 to D18 were then used as baseline data or result variables to compare against the rest of the data gathered from the questionnaire. The purpose of comparison was to identify the key input factor variables or explanatory variables that were related to the software misuse trend. The focus was to answer RQ2 and RQ3.

e. To identify the key relationships stated in step, non-parametric correlation tests were conducted using the SPSS tool. From the non-parametric correlation test results, explanatory variables that were statistically related to Questions D13 to D18 were singled out. Following that, the full listing of all explanatory variables that were statistically related to Questions D13 to D18 were identified, and those that were important were then filtered out for further analysis. Two conditions used for filtering were:

- Condition 1 - The explanatory variables that were statistically related to Questions D13 to D18 
therefore assumed to fall into the investigation framework bounded by these four factors (Technology, Government and Politics; Business Practice, Consumer Mindset)

- Condition 2 - The relationship between Questions D13 to D18 and the explanatory variables must make logical sense even though they were proven to be statistically related. For example, Questions D15 and D20 were statistically related but it would not be really clear to suggest that the respondents' opinions on the use of Iomega Zip drive to share information, was related to the software misuse trend driven by companies not adopting good housekeeping policies to ensure compliance.

f. With the key explanatory variables identified and paired along with their respective relationship with questions from D13 to D18, they were then put through further statistical tests. The aims of having further tests were to confirm that firstly, each paired relationship (explanatory variable + Questions D13-D18) identified through the non-parametric correlation tests did not occur out of mere chance random variability and secondly, the strength of each paired relationship was significant.

g. The Chi-Square test for independence procedure and Fisher Exact probability tests were used to test if the paired relationship did not occur out of mere chance random variability (the confidence level considered as statistically significant to reject the null hypothesis of no relationship). To enable these two tests to be conducted, the data from each paired relationship that was filtered earlier was first cross-tabulated into a $2 \times 2$ contingency table. For the data to fit into the $2 \times 2$ contingency table, the answers to each question were combined to form just two categories. For example, category one comprises "Strongly Agree" and "Agree", while category two comprises of "Strongly Disagree" and "Disagree". The explanatory variables are arranged in the columns of the $2 \times 2$ contingency table. The number of respondents was $30(n=30)$ and that may result in some cells of the $2 \times 2$ contingency table having expected count of less than 5 . Hence, the Chi-Square Test for Independence procedure conducted for each pair of relationship may not have produced a good approximation of result from the $2 \times 2$ contingency table. This limitation was, however, addressed by having each paired relationship tested further through the Fisher Exact probability test. Specific to this study, the confidence level considered to be significant and conclusive shall be more than $95 \%$ or a p-value of less than 0.05 .

h. Finally, the Phi or Cramer's V values were used to determine the strength of each paired relationship. As the test for independence was conducted on a $2 \times 2$ contingency table, the values for Phi and Cramer's V were both interchangeable. Specific to this study, the following guideline used to interpret the Phi or Cramer's V values were as shown in Table 3.

[Insert Table 3]

\section{Findings and Analyses}

Responses from 30 participants representing a response rate of approximately 54\% were compiled and subsequently analyzed. In Section A of the questionnaire, questions related to the respondent's work profile such as industry, functional areas, estimated size of company and annual turnover were asked.

\subsection{Descriptive Statistics - Respondents'Profiles}

The 30 respondents were business professionals representing different industries, functional roles and different levels of work exposure to software usages. For the 8 respondents who selected the industry category as "Others", they belonged to industries such as courier services, design, advertising and real estate. As for respondents' profiles based on the functional areas for which they served, most respondents belonged to the category of the "Individual Contributor". Although there were several respondents who belonged to the senior management categories, the attempt to gather more respondents from these categories were not successful. Hence, the overall balance was slightly inclined towards having more of the total respondents belonging to the "Individual Contributor" category. For respondents who selected the category as "Others", they were either serving as engineer, officer, advisor or consultant. Therefore, this group of respondents was considered as similar to serving in the capacity of individual contributor. There was a fair spread of respondents working across the company size categories that were catered for in the questionnaire.

\subsection{Test of Measurement Model}

The measurement model links each construct in the theoretical model to indicators of the constructs. The strength of measurement model is determined by convergent and discriminant validity tests of the instrument items. Convergent validity reflects the extent to which the indicators of a construct are similar to the other indicators of the same construct. The convergent validity of each construct was assessed by computing Cronbach's alpha and average variance extracted (AVE) by the construct. Table 5 lists the means, standard 
deviations and the convergent validity results for the constructs. On a scale from 1 to 5 , from "strongly disagree" to "strongly agree" respectively, the means of the constructs ranged from 0.76 to 2.35 . Cronbach's alpha for all the constructs (except ITB) were above 0.6 , which is a commonly acceptable level for judging the reliability (Nunnally, 1978 cited in Phang, Sutanto, Kankanhalli, Yan, Tan, and Teo, 2006). The AVE measures the amount of variance that a construct captures from the measurement items and should be greater than 0.50 which indicates that $50 \%$ of the variance has been accounted for (Chin, 1998 cited in Smith, 2008). Convergent validity is adequate when constructs have an average variance extracted (AVE) of at least 0.5 (Fornell and Larcker, 1981 cited in Wixom and Todd, 2005). As shown in Table 4, the AVE values (except UCD, LRU and PUS) exceed the minimum, ranging from 0.5 to 1.1 .

\section{[Insert Table 4]}

Discriminant validity, on the other hand, verifies that the items that demonstrate convergent validity are not highly correlated to any other constructs in the model (Gefen and Straub, 2005). For satisfactory discriminant validity, the AVE from the construct should be greater than the variance (squared correlation) shared between the construct and other constructs in the model (Chin, 1998 cited in Wixom and Todd, 2005). In all the cases as shown in the correlation matrix, the AVE (except LRU and PUS) for each construct is larger than the variance of that construct with all other constructs in the model except for the .

Convergent and discriminant validity are further confirmed when individual items load above 0.5 on their associated factors and when the loadings within construct are higher than those across constructs (Wixom and Todd, 2005), as illustrated in the loading and cross-loadings for the items used in this study. The factor loading values exceed 0.500, an acceptable minimum value (Chin, 1998 cited in Smith, 2008), showing that there is a strong correlation between each of the items on their corresponding construct. Based on these calculations, all items (except LRU, PUS) used in the analysis of the proposed research model can be accepted as internally reliable and consistent in defining the constructs.

\subsection{Software Misuse Trend}

These indirect Questions (D13 to D18) sought respondents' feedback on the current processes and procedures practised by the companies for which they work for. The feedback would have provided a useful starting point to gauge the current state of software usages and, as well as to understand the general internal policies of today's businesses with regard to software rights. The data gathered from these questions were illustrated (see Figure 2). An additional optional question (Question D19) for respondents to give feedback on other business practices that were not listed in this section was also provided. However, there was no response to this optional question and therefore it was omitted from the analysis.

For each of the key business practices (Questions D13 to D18) that were related to software usages listed, the percentage of respondents who indicated that the companies they worked for either seldom or did not employ such practices are 60\% for Question D13, 77\% for Question D14, 70\% for Question D15, 67\% for Question D16, $73 \%$ for Question D17, and $80 \%$ for Question D18. Clearly, there was a general trend of companies not adopting the appropriate business practices to regulate internal software usages. Although it was not directly obvious, the failure of companies to adopt those control practices actively did suggest possible misuse within the organizations. Most respondents answered 'Seldom" and within this answer category, one could also assume that there were suspected cases of respondents being unwilling to disclose sensitive truth about their respective organizations not adopting these practices at all. In addition, it would also be fair to assume that cases of misuse could be a result of either oversight or deliberation. Oversights or deliberation, whichever the case might be, the object of Questions D13 to D18 was merely to determine the presence or to confirm the initial suspicion of software misuse trend.

\section{[Insert Figure 2]}

In addition to the assertion that the lack of good software usage control practices in place did suggested possible software misuse, it has also been observed that the answer trends that were received from the 30 respondents to these six questions were very similar and consistent. In other words, all the software usage control practices that were listed in this set of questions were either not or seldom practised. Chi-Square Independence tests were conducted on two sets of randomly paired questions (Questions D14/D15 and D15/D16) to confirm if the consistency observed in the answers to the six questions occurred out of mere chance random variability. In both cases, it was confirmed with more than $99.9 \%$ confidence that the consistencies in the answers did not occur out of mere random variability with X2 $=13.50$ (Questions D14/D15) and X2 $=17.86$ (Questions D15/D16).

Since some of the cells in the $2 \times 2$ contingency tables have expected value of less than 5 , and this implied that the 
approximation using Chi-Square may not be entirely accurate. This limitation was addressed by running the Fisher Exact Probability test. Using the same sets of paired questions, the test results $(F=0.000884173$ for Questions D14/D15; F= 6.36046E-05 for Questions D15/D16) provide further evidences to confirm with more than $99.9 \%$ confidence that the consistencies in the answers were not by mere chance random variability.

\subsection{Explanatory Factors for Software Misuse}

Having confirmed the presence of software misuse trend, Questions D13 to D18 were therefore used as the outcome variables, serving as the baseline data for further analysis. Four sets of non-parametric correlation tests were conducted with the objective of finding explanatory variables that were related to the outcome variables. The criteria established in Section 4.2 were then used to filter off the redundant relationships and the following remaining 9 pairs of variables were found to be statistically related (see Table 5).

[Insert Table 5]

Each of the paired relationships was put through further test to confirm if the relationship did occur out of mere chance random variability (Chi-Square Test for Independence and Fisher Exact Probability test) and if the strength between the relationship (Phi and Cramer's V values) was statistically significant enough to be conclusive.

\subsection{Test Results - Explanatory Factors for Software Misuse}

Test on Paired Number 1 (D18/B14) produced (Chi-Square P-value $=0.542$, Fisher Exact P- value $=0.501$, Phi value $=0.11)$. Although non-parametric correlation test showed the existence of relationship between the two variables, suggesting that technology was related to software misuse trend, the Chi-Square and Fisher Exact Probability test values did not provide significant statistical evidence to reject the null hypothesis of no relationship with confidence. Phi value computed confirmed that the strength of relationship between the pair of variables was weak.

For example, test on Paired Number $2(\mathrm{D} 14 / \mathrm{B} 27)$ produced (Chi-Square P-value $=0.976$, Fisher Exact P-value $=$ 0.660 , Phi value $=0.01)$. Although non-parametric correlation test $(0.394)$ showed the existence of relationship between the two variables, suggesting that the lack of awareness to the available copy protection technologies contributed in part to the current software misuse trend, the Chi-Square and Fisher Exact Probability test values did not provide significant statistical evidence to reject the null hypothesis of no relationship with confidence. Phi value computed confirmed that there was no relationship between the pair of variables.

Test on Paired Number 3 produced (Chi-Square $P$ value $=0.00002$, Fisher Exact $P$ value $=0.00088$, Phi value $=$ 0.67). The non-parametric correlation test (0.699) clearly showed the existence of a strong relationship between the two variables, suggesting that the lack of awareness to the current law and regulation has contributed to the current software misuse trend. In addition the Chi-Square and Fisher Exact Probability test values provided significant statistical evidence to reject the null hypothesis of no relationship with more than $99.9 \%$ confidence. Phi value computed has also shown that there was a strong and significant relationship between the pair of variables.

Table 6 summarises the results of non-parametric correlation tests with respect to explanatory and outcome variables for the remaining 6 pairs of questions.

\section{[Insert Table 6]}

\subsection{Four Key Factors and Software Misuse Trend}

Through the analyses of the data gathered from the questionnaire and along with the statistical tests executed, several findings were found. Firstly, from the data gathered, there was a noticeable software misuse trend shown among the companies where the thirty respondents worked in. Secondly, it was also clear that the software misuse trend identified from the data was closely related to the current software piracy and counterfeiting issue at hand.

a. Technology Factor: Based on Questions from B1 to B47, the following key trends were observed:

- The respondents' exposure to computer technologies and copy-enabled technologies were high.

- The respondents' awareness level to copy protection technologies was low.

In analyzing the data further, the non-parametric correlation test revealed that the exposure to copy-enabled technology and the lack of awareness to copy protection technologies were related to software misuse trend. However, further tests did not provide any conclusive evidence to support these observations and relationships. Therefore, the discussion on technology could not be supported given that there was a lack of significant 
evidence.

b. Government and Politics Factor: From Questions from $\mathrm{C} 1$ to $\mathrm{C} 60$, the following key trends were observed:

- Although there were legal framework in place, the awareness level to the laws and regulations displayed by the respondents were generally low.

- The enforcement measures in place have not been executed effectively.

- The efforts to provide education or communication on proper software usages were minimal.

The non-parametric test conducted did also support the observations. Subsequent tests had revealed significant evidences to support the assertion that despite the presence of appropriate legal framework, the lack of awareness to the laws and regulations did contribute to the current software misuse trend $\left(X^{2}=13.496, P\right.$-value $=0.000239$, $\mathrm{df}=1$ ). In addition, there was also evidence to support the assertion that the lack of tough laws was another contributing factor to the software misuse trend $\left(\mathrm{X}^{2}=9.4585, \mathrm{P}\right.$-value $\left.=0.002102, \mathrm{df}=1\right)$. There was also significant evidence to support the assertion that the software piracy and counterfeiting issue was due to the minimal effort being made in the delivery of communication and education that are related to the proper use of software $\left(\mathrm{X}^{2}=4.6584, \mathrm{P}\right.$-value $\left.=0.0309, \mathrm{df}=1\right)$.

c. Business Practice Factor: The following key trends were identified (Questions from D1 to C38):

- The security and measures in place to ensure proper software usage within the companies were lacking.

- Most companies do not place enough emphasis on the implementation of proper software usage policies.

- The high cost of software ownership was a barrier to ensure software compliance.

The non-parametric correlation test conducted did reveal that the observation made on the high cost of software ownership had no relationship with the software misuse trend. Further tests had revealed significant evidence to support the assertion that for most companies, policies on proper software usages was of the lowest priority as compared to other business initiatives. As a result, most companies perceived compliance as the lowest priority in managing software policies and this in turn was a contributing factor to the software misuse trend (X2 = 6.6786, P-value $=0.00976, \mathrm{df}=1)$. However, as mentioned earlier, there was no evidence from any of the statistical tests conducted to support the observation that the high cost of software ownership was related to the software misuse trend. The lack of evidence on the high cost of software being related to the software misuse trend was also a deviation within the scope of this study.

d. Consumer Mindset Factor: From Questions from E1 to E18, the following key trends were observed:

- The high price of software provided an attractive incentive for software piracy and counterfeiting.

- Consumers' generally perceived the existing law and regulation to be ineffective against software misuse.

- Having good consumer education that is related to proper software usage is effective against the software misuse trend.

The non-parametric correlation tests revealed evidences to support the observation made on the effectiveness of education on proper software usage being related to software misuse trend. However, the same non-parametric correlation test did not reveal evidence to support the other observations made. There was no evidence from further testing to support the assertion that the consumers' perception on the ineffectiveness of laws and regulations had any impact on the software misuse trend $(\mathrm{X} 2=3.333$, P-value $=0.0679, \mathrm{df}=1)$. In addition, there was also no further test evidence to support the assertion that high software price played a part in the software misuse trend $(\mathrm{X} 2=0.2586, \mathrm{P}$-value $=0.61107, \mathrm{df}=1)$. On the other hand, there was significant evidence in supporting the assertion that education is an effective way against software misuse $(\mathrm{X} 2=5.625$, P-value $=0.01771, \mathrm{df}=1$ ).

\subsection{Explanatory Variables Relating to Software Misuse Trend}

Through the analyses of the data gathered from the questionnaire and along with the statistical tests executed, several findings were found. Firstly, there was a noticeable software misuse trend shown among the companies where the 30 respondents worked in. Secondly, it was also clear that the software misuse trend identified from the data was closely related to the current software piracy and counterfeiting issue at hand.

There were five explanatory variables, tested to be significantly related to software misuse trend identified from the research. Ranked in order of statistical significance based on the extent of confidence level and the strength 
of the relationship, the explanatory variables were:

a. The lack of awareness to law and regulation ((D14/C6). This was the most compelling explanatory variable related $(0.699)$ to the software piracy and counterfeiting issue. It was proven that the relationship did not occur out of mere chance random variability (Chi-Square P-value $=0.00002$, Fisher Exact P-value $=$ 0.00088). Significance evidence was also found to support the fact that the explanatory variable was strongly related $(\mathrm{Phi}$ value $=0.67)$ to the issue of software piracy and counterfeiting. Therefore, it can be concluded that any effort to improve the awareness level would potentially prove to have a positive effect on the software piracy and counterfeiting trend.

b. The lack of tough enforcement measures or penalties (D14/D36). This was another explanatory variable which was proven to be significantly related $(0.551)$ to the software piracy and counterfeiting issue. Likewise, this relationship did not occur out of mere chance random variability (Chi-Square P-value $=0.002$, Fisher Exact P-value $=0.004)$. In addition, there was significant evidence to show that there was a strong relationship (Phi value $=0.56$ ) between the explanatory variable and the issue of software piracy and counterfeiting. Therefore, it can also be concluded that the presence of tough enforcement measures or penalties, taken against software misuse would have a positive effect on the software piracy and counterfeiting trend.

c. Compliance being the lowest priority in software policies (D14/D11). There was evidence to suggest that this explanatory variable was related $(0.503)$ to the software piracy and counterfeiting issue, and that the relationship did not occur out of mere chance random variability (Chi-Square P-value $=0.009$, Fisher Exact $\mathrm{P}$-value $=0.015$ ). However, further test had shown that although the relationship was substantial, it was more than just indicative rather than conclusive (Phi value $=0.47$ ). As such, having companies place more emphasis on software policies so as to address the compliance issue may have improved the software piracy and counterfeiting trend. However, the research did not offer significant evidence to prove that this suggestion was entirely conclusive.

d. Training and education on proper software usages (D16/E14). There was evidence to suggest that this explanatory variable was related $(0.524)$ to the software piracy and counterfeiting issue, and that the relationship did not occur out of mere chance random variability (Chi-Square P-value $=0.017$, Fisher Exact $\mathrm{P}$-value $=0.02)$. However, further test had shown that although the relationship was substantial, it was more than just indicative rather than conclusive $(\mathrm{Phi}$ value $=0.43$ ). This suggested that regular training and education for software users on topics such as software usage rights, software usage laws, software usage regulations, violation penalties and so forth may have positive effect on the software piracy and counterfeiting trend. However, the research did not offer significant evidence to prove that this suggestion was entirely conclusive.

e. Companies adopting the practice to provide regular employee training on proper software usages (D13/C55). There was evidence to suggest that this explanatory variable was related $(0.523)$ to the software piracy and counterfeiting issue, and that the relationship did not occur out of mere chance random variability (Chi-Square P-value $=0.03$, Fisher Exact P-value $=0.04)$. However, further test had shown that the strength of the relationship was merely moderate. Moreover, it was also more than just indicative rather than conclusive (Phi value $=0.39$ ). This suggested that with more companies adopting the practice of providing constant training to employees on proper software usages, the issue of software piracy and counterfeiting may well have improved. However, the research once again did not offer significant evidence to prove that this suggestion was entirely conclusive.

Particularly, there were insufficient evidences found to support technologies, software pricing and cost of software ownership as being the factors that were related to the software piracy and counterfeiting issue. In cases where evidences were found linking these factors to the software piracy and counterfeiting issue, subsequent tests have revealed that the relationships either occurred out of coincidence or were insignificant to be considered as conclusive. To comment further, the gaps could be attributed to several factors:

i. There were several constraints encountered in the process of working through this study. One of such constraint was that this study was concerned with access to sensitive business data and therefore access to certain information was limited. Another constraint was that there were missing answers to certain questions that were posted and that would have denied this dissertation the critical data that were needed for analysis. Logistic was also another constraint as there were difficulties encountered in administrating a questionnaire that was targeted at respondents with certain level of knowledge to the issue at hand and who were at the same time, working across different companies. 
ii. One limitation was the sample size of 30 may had contributed to certain analysis producing less than conclusive evidences. Another limitation may be related to how the questions in the questionnaire were phrased and also the large number of questions (167 questions) that the respondents were expected to answer. As such, whenever possible, the questions were formatted into structured groupings such that it was less taxing for the respondents to complete the questions. The lack of diversity in the targeted respondents may also be another limitation in this study. As shown from the actual data gathered, a significant proportion of the respondents were not holding senior level positions in the companies they worked for and as a matter of relevance, questions that were concerned with company policy making were best answered by senior executives.

\section{Conclusion and Future Work}

This is exploratory study conducted to investigate the key factors and counter measures around the software piracy and counterfeiting issues. Using a questionnaire based on four key factors, views from 30 respondents, representing different industries, functional roles and different levels of work exposure to software usages working in Singapore, were collected. Through the structural use of statistical tests, it was shown that the lack of awareness to software usage laws and regulations, the lack of tough enforcement measures and penalties, and the lack of educational programs catering to the proper usage of software seemed to be the key factors behind the software piracy and counterfeiting issues.

\subsection{Recommended Measures to Counter Software Privacy and Counterfeiting}

Findings also indicate that factors contributing to the current software piracy and counterfeiting issue are interrelated. As such, any effort to resolve or improve would have to be undertaken in a holistic approach. Although there are currently software usage laws and regulations in place, efforts must also be made to review these laws and regulations on regularly basis such that the relevance are in pace with the advancement in the software industry. Most important of all, the presence of software usage laws and regulations alone would not be helpful in improving the software piracy and counterfeiting issue if there is no effort to educate software users on the implication of these laws and regulations $(\mathrm{X} 2=13.496, \mathrm{P}$-value $=0.000239, \mathrm{df}=1)$. Additionally, in cases when there are any non-compliances, the need for tough enforcement would have to be executed in a timely manner $(\mathrm{X} 2=9.4585, \mathrm{P}$-value $=0.002102, \mathrm{df}=1)$.

At the business level, it has been observed that the lack of priority placed to comply with the current software usage laws and regulations could be a factor behind the software misuse trend $(\mathrm{X} 2=6.6786, \mathrm{P}$-value $=0.00976, \mathrm{df}$ $=1$ ). The inclusion of swift enforcement effort driven by the government will trigger companies in Singapore to adopt the policy of actively driving continuous education and communication on the implication of the software usage laws and regulations across to employees $(\mathrm{X} 2=4.6584$, $\mathrm{P}$-value $=0.0309, \mathrm{df}=1)$. Such positive programs at the business level would have improved the software piracy and counterfeiting issue. As with the new provisions in the Singapore Copyright Law, making corporate end user piracy a criminal offence as of 1st January 2005, the activities leading to the implementation have included substantial communication and education effort lead by the relevant authorities. The collaborative effort committed by the BSA, the Singapore Police Force, the Attorney General's Chambers, the Ministry of Law and the Intellectual Property Office of Singapore have reshaped the way companies in Singapore approach the issue of software resource management. This would in turn drives similar positive action that would be expected at the consumer or end-user level, where the incentives to using unlicensed software product would then be weighted carefully against a series of possible punishments due to any infringement.

At the consumer level, there will be additional effort needed to delivery continuous educational programs to correct the perception of using unlicensed software $(\mathrm{X} 2=5.625$, P-value $=0.01771$, df $=1)$. The TV advertisement that was shown across most Singapore TV channels, which equated using unlicensed software to stealing, drove a good message across to all households including the young generation. It was a positive step undertaken where overtime, would have eroded the demand for unlicensed software products and consequently leading to minimal incentives for software pirating and counterfeiting.

\subsection{Future Work}

We believe the findings would be useful to managers of software companies and policy-makers when reviewing the existing software protection policies, laws and regulations, such that any flaws or loopholes can be easily identified. The key issues highlighted in this study may also facilitate further investigation on software usage infringements by pointing directly to potential areas of factors. At a macro level, it is beneficial to develop an understanding of this issue since this is known to have crippled the IT growth of countries, which in turn has resulted in a huge negative impact on the economy. 
The limitations and constraints highlighted in this study would have to be addressed for future works that are related to the issue of software piracy and counterfeiting. In addition, the findings from the data collected and some key responses from the questionnaire have raised several issues worthy of further research and discussions.

As this is an initial study, we intend to embark upon a series of future studies to address the following recommendations:

- The subject on cost of software ownership or software pricing need to be addressed further even though there was no concrete evidence found to support these factors as being responsible for the current software piracy and counterfeiting issue. While there was no significant evidence found from this study, the factors were nevertheless highlighted to be the major motivation behind the software piracy and counterfeiting issue. The most compelling was the almost unanimous answers observed from Question E7. Although this study did not yield sufficient evidence to conclude that software price is a factor to software piracy and counterfeiting issue, the answers observed did suggest that this factor should continue to be explored in future work.

- Extending the research to cover a wider scope of work such as conducting comparative studies on the software misuse trend among different industries, and as well as among different regions. Findings that are revealed from industries or countries with lower misuse trend would have provided case studies of possible improvement models to be implemented in industries or countries with higher misuse trend. In addition, the findings may well be different if the same study is conducted in other well-developed or less-developed regions (due to the different level of affluence and wealth of the people).

- The issue of software piracy and counterfeiting has an enormous economic impact on the world. Lowering the piracy rate will stimulate local economic activity, generate government revenue, create job growth and cultivate future innovation (BSA, 2004). However, the issue at hand is highly dynamic, given the intangibility of software and the rapid advancement made in the area of data transfer technologies. Therefore one area of focus for future works is on researching possible refinements to the software usage laws and regulations. This is essential so as to ensure that all possible legal pitfalls are timely addressed before further economical losses are incurred.

\section{References}

Bagchi, K., Kirs, P. \& Cerveny, R. (2006). Global software piracy: Can economic factors alone explain the trend? Communications of the ACM, 49(6), 70-76. ACM New York.

Business Software Alliance (2004). First Annual BSA and IDC Global Software Piracy Study. [Online] Available: http://w3.bsa.org/globalstudy/2004-Global-Piracy-Study.cfm (Nov 16 Nov, 2009).

Business Software Alliance (2005). Second Annual BSA and IDC Global Software Piracy Study. Retrieved 16 Nov 2009 from http://w3.bsa.org/globalstudy/Global-Piracy-Study-Archives.cfm.

Business Software Alliance (2006). Third Annual BSA and IDC Global Software Piracy Study. Retrieved 16 Nov 2009 from http://w3.bsa.org/globalstudy/2006study.cfm.

Business Software Alliance (2008). Fifth Annual BSA and IDC Global Software Piracy Study. Retrieved 16 Nov 2009 from http://global.bsa.org/idcglobalstudy2007/studies/2007_global_piracy_study.pdf.

Business Software Alliance (2009). Sixth Annual BSA and IDC Global Software Piracy Study. Retrieved 16 Nov 2009 from http://global.bsa.org/globalpiracy2008/studies/globalpiracy2008.pdf

Chesterman, J. and Lipman, A. (1988). The Electronic Pirates: DIY Crime of the Century. London: Routledge, Chapman and Hall.

Chin, W. W. (1998). The partial least squares approach for structural equation modelling. Modern methods for business research. G.A. Marcoulides: Lawrence Erlbaum Associates.

Cohen, E. (1989). College students believe piracy is acceptable. Journal of Information Systems Education, 1(3), 23-34. West Lafayette.

Cosovanu, C. (2006), Open Source Software in Eastern Europe and Other Emerging Markets: The Moral Alternative to Piracy?. Journal of Internet Law, Vol. 9, p. 3, January 2006.

Fornell, C., \& Larcker, D. F. (1981). Structural equation models with unobservable variables and measurement errors. Journal of Marketing Research, 18, 39-50.

Gefen, D., \& Straub, D. W. (2005). A practical guide to factorial validity using PLS-Graph: Tutorial and annotated example. Communications of the Association for Information Systems, 16, 91-109.

Gopal, R., \& Sanders, L. (1997). Preventive and deterrent controls for software piracy. Journal of Management Information Systems, 13(4), 29-47. Armonk. 
Gopal, R.D. \& Sanders, G.L. (2000). Global software piracy: you can't get blood out of a turnip. Communications of the ACM, 43(1), 82-89. ACM New York.

Gurnsey, J. (1995). Copyright Theft. Hampshire: Aslib Gower.

Hawamdeh, S.A. Hart, T.L. (2002). Information and Knowledge Society. Singapore: McGraw-Hill.

Hill, C.W.L. (2007). Digital piracy: Causes, consequences, and strategic responses. Asia Pacific Journal of Management, 24(1), 9-25. Springer Science \& Business Media B.V.

Lesser, W. (2001). The Effects of TRIPS-Mandated Intellectual Property Rights On Economic Activities In Developing Countries. Prepared under WIPO Special Service Agreement. Cornell University.

Nunnally, J. C. (1978). Psychometric Theory (2nd ed.). New York: McGraw-Hill.

Peace, A.G. (1997). Software piracy and computer-using professionals: a survey. Journal of

Phang, C.W., Sutano, J., Kankanhalli, A., Yan, L., Tan, B.C.Y., \& Teo, H.H. (2006). Senior Citizens' Acceptance of Information Systems: A Study in the Context of E-Government Services. IEEE Transactions on Engineering Management, 53(4), 555-569.

Preece, J., Benyon, D., Davies, G., Keller, L. and Rogers, Y. (1993). A Guide to Usability: Human Factors in Computing. Addison-Wesley.

Sherwood, R.M. (1990). Westview Special Studies in Science, Technology, and Public Policy. Intellectual Property and Economic Development. Colorado: Westview Press, Inc.

Smith, T., J. (2008). Senior Citizens and E-commerce Websites: The Role of Perceived Usefulness, Perceived Ease of Use, and Web Site Usability. Information Science, 11.

United Nations Conference on Trade and Development (UNCTAD). (1975). The Role of the Patent Systems in the Transfer of Technology to Developing Countries. New York: United Nations.

Wixon, B. H., \& Todd, P. A. (2005). A theoretical Integration of User Satisfaction and Technology Acceptance. Information Systems Research, 16 (1), 85-102.

Yang, D., Sonmez, M., Bosworth, D., \& Fryxell, G. (2008). Global software piracy: Searching for further explanations. Journal of Business Ethics, Springer Netherlands.

Table 1. Factors and Variables Leading to Software Piracy and Counterfeiting

\begin{tabular}{|c|c|c|}
\hline Factors & Contributing Variables & Supporting Variables \\
\hline \multirow[t]{3}{*}{ Technology } & Computer technologies & $\begin{array}{l}\text { SV\#1: Computer technologies that facilitated easy access } \\
\text { to software }\end{array}$ \\
\hline & Copy-enabled technologies & $\begin{array}{l}\text { SV\#2: Copy-enabled technologies that allowed software } \\
\text { programs to be copied easily. }\end{array}$ \\
\hline & Copy-protection technologies & $\begin{array}{l}\text { SV\#3: Copy protection technologies that were developed } \\
\text { specifically to prevent copying of software programs. }\end{array}$ \\
\hline \multirow[t]{3}{*}{ Government } & Legal framework & $\begin{array}{l}\text { SV\#4: The legal framework that defined how software } \\
\text { programs should be protected. }\end{array}$ \\
\hline & Regulations and enforcement & $\begin{array}{l}\text { SV\#5: Regulations and enforcement that addressed the } \\
\text { issue of violation and enforcement. }\end{array}$ \\
\hline & Technology gap & $\begin{array}{l}\text { SV\#6: Technology gap determined how much balance is } \\
\text { needed between software protection and software fair use. }\end{array}$ \\
\hline \multirow[t]{3}{*}{$\begin{array}{l}\text { Business } \\
\text { Practice }\end{array}$} & Security and Measures & $\begin{array}{l}\text { SV\#7: Security and measures related to business software } \\
\text { usages that should be implemented. }\end{array}$ \\
\hline & Software pricing & $\begin{array}{l}\text { SV\#8: High software price that influences how business } \\
\text { prioritizes software policies. }\end{array}$ \\
\hline & Policies & $\begin{array}{l}\text { SV\#9: Internal business policies drive employees' } \\
\text { awareness level on the proper usage of software. }\end{array}$ \\
\hline \multirow[t]{3}{*}{$\begin{array}{l}\text { Consumer } \\
\text { Mindset }\end{array}$} & Access to Technology & $\begin{array}{l}\text { SV\#10: Easy access to technology influences the } \\
\text { mindset of software consumers on correct } \\
\text { software usage. }\end{array}$ \\
\hline & Education & $\begin{array}{l}\text { SV\#11: Training and education programs improve } \\
\text { software users' understanding on the } \\
\text { implication of software laws and regulations. }\end{array}$ \\
\hline & Cost of Ownership & $\begin{array}{l}\text { SV\#12: High cost of software ownership shape } \\
\text { software consumers' mindset on the issue of } \\
\text { copyrights. }\end{array}$ \\
\hline
\end{tabular}


Table 2. Measurement Scales: Constructs and Supporting Variables

\begin{tabular}{|c|c|c|}
\hline Qn & Item & Description \\
\hline \multicolumn{3}{|c|}{ Technology Factor (B1-B47) } \\
\hline B1-B11 & UCD & Extent of usage of the following computer devices in your current work environment. \\
\hline B13-B24 & ESI & Extent of effectiveness of technologies in terms of sharing software or electronic information. \\
\hline B26-B34 & ASP & Extent of your awareness of the following in terms of software protection. \\
\hline B36-B44 & ESP & Extent of effectiveness of technologies in terms of protecting software or electronic \\
\hline \multirow[t]{2}{*}{ B46-B47 } & ASC & information. \\
\hline & & Extent of your agreement that the availability of technologies facilitates software copying \\
\hline \multicolumn{3}{|c|}{ Government and Politics Factor (C1-C54) } \\
\hline $\mathrm{C} 1-\mathrm{C} 2$ & LRU & Extent of your agreement on laws and regulations to govern the use of software. \\
\hline $\mathrm{C} 3-\mathrm{C} 10$ & ALR & Extent of awareness of the following laws and regulations. \\
\hline $\mathrm{C} 12-\mathrm{C} 23$ & IUS & Extent of your agreement on activities that constitute illegal use of software. \\
\hline $\mathrm{C} 25-\mathrm{C} 33$ & EPL & Extent of effectiveness of present laws against the following activities. \\
\hline $\mathrm{C} 35-\mathrm{C} 42$ & $\mathrm{JCA}$ & Extent of agreement of justification of corrective action against software misuse. \\
\hline $\mathrm{C} 44-\mathrm{C} 51$ & EEU & $\begin{array}{l}\text { Effectiveness of following media in providing educational information on the corrective use of } \\
\text { software. }\end{array}$ \\
\hline C53-C59 & FEU & $\begin{array}{l}\text { Frequency of following media in providing educational information on the corrective use of } \\
\text { software. }\end{array}$ \\
\hline \multicolumn{3}{|c|}{ Business Practice Factor (D1-D38) } \\
\hline D6-D11 & FSP & Frequency of software purchase based on the following activities. \\
\hline D13-D18 & FCP & Frequency of checks and practices on regulating use of software. \\
\hline D20-D25 & ERU & Extent of effectiveness of practices on regulating use of software. \\
\hline D27-D37 & BLS & Extent of agreement of barriers to maintain legal software licenses. \\
\hline \multicolumn{3}{|c|}{ Consumer Mindset Factor (E1-E18) } \\
\hline E1-E7 & AUS & Extent of agreement on the use of legal software. \\
\hline E8-E12 & PUS & Extent of agreement of parties responsible for the use of legal software. \\
\hline E14-E17 & ESM & Extent of effectiveness of measures against software misuse. \\
\hline
\end{tabular}

Table 3. Phi or Cramer's Values on Strengths of Paired Relationship

\begin{tabular}{cl}
\hline Range of Phi or Cramer's Values & Strengths of Paired Relationship \\
\hline 0.50 or higher & very strong and significant relationship \\
0.40 to 0.49 & substantial relationship \\
0.20 to 0.39 & moderate relationship \\
0.10 to 0.19 & low relationship \\
0.09 or lower & no relationship \\
\hline
\end{tabular}


Table 4. Descriptive Statistics and Convergent Validity of Constructs

\begin{tabular}{llllll}
\hline Construct & Code & Mean & SD & Alpha & AVE \\
\hline Usage of computer devices & UCD & 2.33 & 0.31 & 0.566 & 0.4 \\
Effectiveness of technologies & ESI & 1.03 & 0.44 & 0.763 & 0.7 \\
Awareness of software protection & ASP & 1.48 & 0.79 & 0.915 & 1.1 \\
Effectiveness of software protection & ESP & 1.50 & 0.60 & 0.831 & 0.8 \\
Availability of software copying & ASC & 0.93 & 0.71 & 0.933 & 0.5 \\
Law and regulations of use & LRU & 1.10 & 0.60 & 0.681 & 0.3 \\
Awareness of law and regulations & ALR & 1.72 & 0.73 & 0.898 & 0.9 \\
Illegal use of software & IUS & 1.11 & 0.52 & 0.906 & 0.5 \\
Effectiveness of present law & EPL & 2.35 & 0.58 & 0.920 & 0.5 \\
Justification of corrective actions & JCA & 1.75 & 0.68 & 0.872 & 0.6 \\
Effectiveness of media education on corrective use & EEU & 1.41 & 0.61 & 0.857 & 0.9 \\
Frequency of media education on corrective use & FEU & 2.00 & 0.62 & 0.878 & 0.5 \\
Frequency of software purchase & FSP & 1.16 & 0.54 & 0.843 & 0.6 \\
Frequency of checks and practices of use & FCP & 1.73 & 0.61 & 0.932 & 0.6 \\
Effectiveness of regulating software use & ERU & 1.47 & 0.77 & 0.926 & 0.9 \\
Barriers maintaining legal software licenses & BLS & 1.24 & 0.57 & 0.887 & 0.6 \\
Agreement on use of software & AUS & 1.02 & 0.37 & 0.634 & 0.5 \\
Parties responsible for use of legal software & PUS & 1.01 & 0.53 & 0.864 & 0.4 \\
Effectiveness of measures against software & ESM & 1.08 & 0.54 & 0.065 & 0.6 \\
\hline
\end{tabular}

Table 5. Statistically related Pairs of Variables

Paired Number

2

3

4

5

6

7

8

9
Outcome Variable

Question D18

Question D14

Question D14

Question D14

Question D13

Question D14

Question D13

Question D18

Question D16
Explanatory Variable

Question B14

Question B27

Question C6

Question D36

Question C55

Question D11

Question D32

Question E7

Question E14 
Table 6. Non-parametric correlation tests, explanatory and outcome variables

\begin{tabular}{|c|c|c|c|c|c|c|c|}
\hline No & $\begin{array}{c}\text { Pairs of } \\
\text { Questions }\end{array}$ & $\begin{array}{c}\text { Variables in relation to Software } \\
\text { Misuse Trend }\end{array}$ & $\begin{array}{l}\text { Chi-square } \\
\text { p-value }\end{array}$ & $\begin{array}{c}\text { Fisher } \\
\text { Exact } \\
\text { p-value }\end{array}$ & $\begin{array}{c}\text { Phi } \\
\text { value }\end{array}$ & $\begin{array}{l}\text { Non-parametric } \\
\text { correlation }\end{array}$ & $\begin{array}{l}\text { Significant } \\
\qquad(\mathrm{Y} / \mathrm{N})\end{array}$ \\
\hline 1 & D18/B14 & Copy-enabled technology. & 0.542 & 0.501 & 0.11 & 0.500 & $\mathrm{~N}$ \\
\hline 2 & $\mathrm{D} 14 / \mathrm{B} 27$ & $\begin{array}{l}\text { Lack of awareness to the available } \\
\text { copy protection technologies. }\end{array}$ & 0.976 & 0.660 & 0.01 & 0.394 & $\mathrm{~N}$ \\
\hline 3 & $\mathrm{D} 14 / \mathrm{C} 6$ & $\begin{array}{l}\text { Lack of awareness of current law } \\
\text { and regulation. }\end{array}$ & 0.0002 & 0.0008 & 0.67 & 0.699 & $\mathrm{Y}$ \\
\hline 4 & D14/D36 & $\begin{array}{l}\text { Lack of tough law and enforcement } \\
\text { measures }\end{array}$ & 0.002 & 0.004 & 0.56 & 0.551 & Y \\
\hline 5 & $\mathrm{D} 13 / \mathrm{C} 55$ & $\begin{array}{l}\text { Lack of practices of providing } \\
\text { training and education to } \\
\text { employees on proper software } \\
\text { usage }\end{array}$ & 0.03 & 0.04 & 0.39 & 0.523 & Y \\
\hline 6 & D14/D11 & $\begin{array}{l}\text { Low priority in compliance when } \\
\text { managing software policies. }\end{array}$ & 0.009 & 0.015 & 0.47 & 0.503 & $\mathrm{Y}$ \\
\hline 7 & $\mathrm{D} 13 / \mathrm{C} 32$ & Presence of law effective. & 0.067 & 0.084 & 0.33 & 0.485 & $\mathrm{~N}$ \\
\hline 8 & D18/E7 & Price of software. & 0.611 & 0.8 & 0.09 & 0.372 & $\mathrm{~N}$ \\
\hline 9 & D16/E14 & $\begin{array}{l}\text { Training and education effective } \\
\text { against software misuse. }\end{array}$ & 0.017 & 0.02 & 0.43 & 0.524 & $\mathrm{Y}$ \\
\hline
\end{tabular}




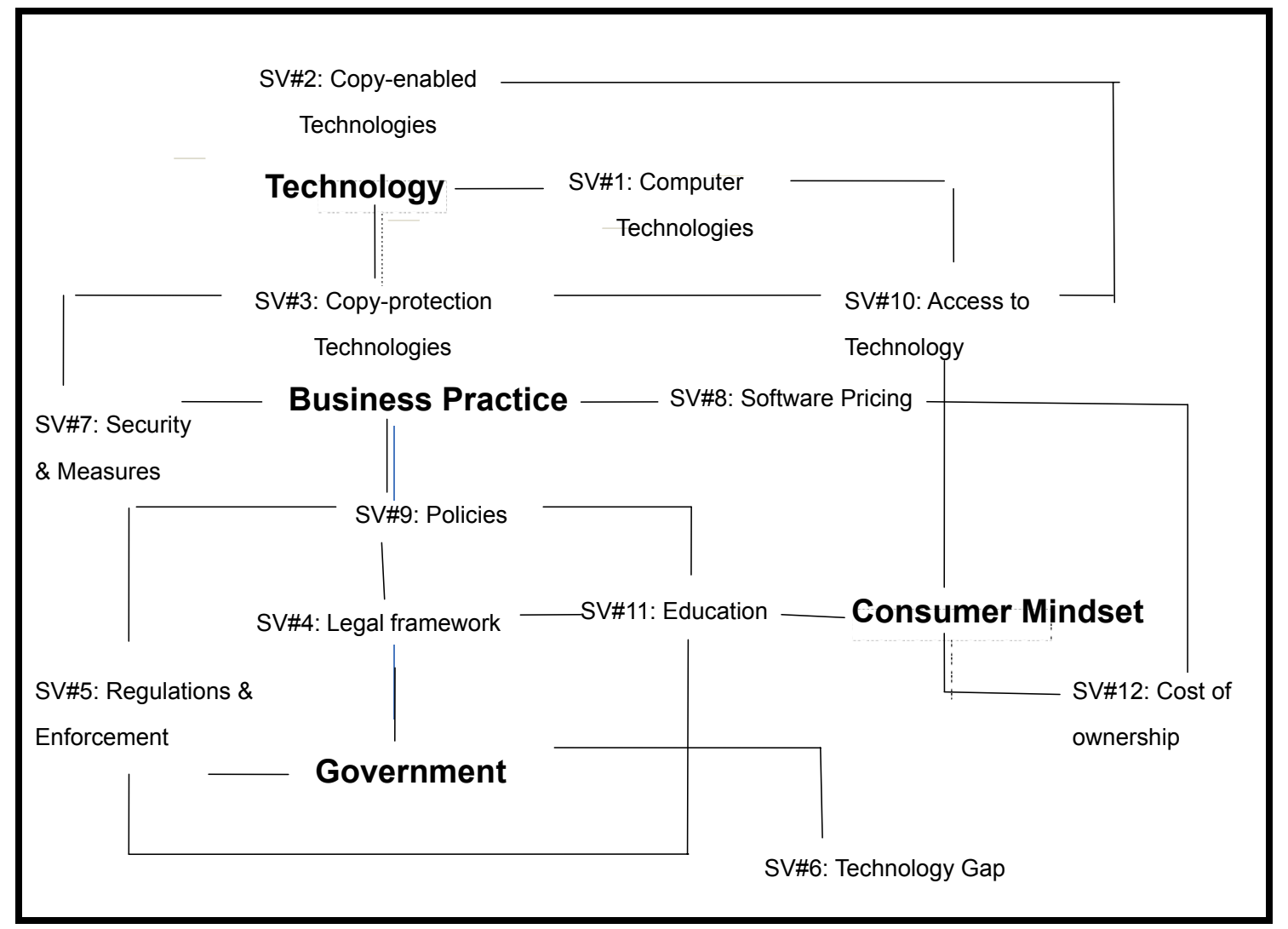

Figure 1. Conceptual Model of Piracy and Counterfeiting Factors

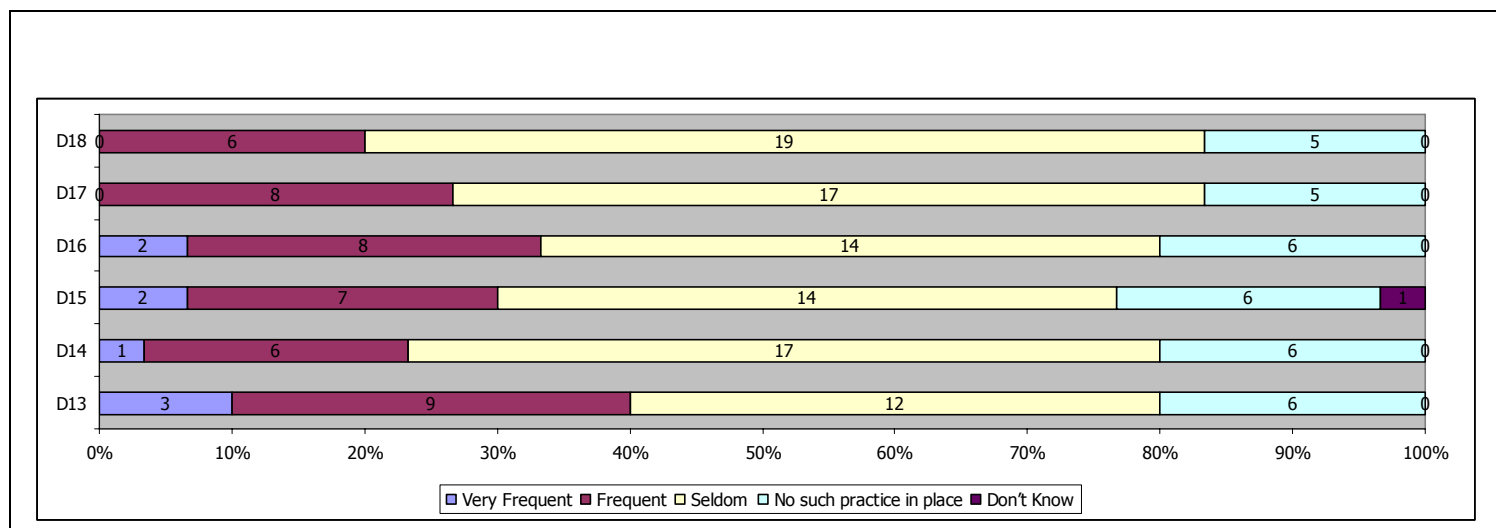

\section{Legend to questions asked :}

D13 - Software inventory audit

D14 - Education or training on correct software use

D15 - Housekeeping to ensure software usage compliance

D16 - Company wide software usage compliance alerts or reminders

D17 - Review/Update existing software usage processes and policies

D18 - Taking disciplinary action against software misuse

Figure 2. Questions D13 to D18 